\title{
French Validation of the Life Engagement Test Scale
}

Fabienne Lemétayer $^{1, \star}$, Manon Florquin ${ }^{1}$, Laura Lepage ${ }^{1}$, Laura Saez ${ }^{1}$ and Jean-Baptiste Lanfranchi ${ }^{2}$

${ }^{1}$ Université de Lorraine, APEMaC, F - 57000 Metz, France

${ }^{2}$ Université de Paris and Univ. Gustave Eiffel, LaPEA, F-92100 Boulogne-Billancourt, France

\begin{abstract}
Background: The Life Engagement Test was developed by Scheier et al. (2006) to assess individuals' engagement in life through the importance they give to their life goals. The purpose of this article is to present the French validation of the Life Engagement Test (LET-F).
\end{abstract}

Methods: The LET was first translated into French using the back translation method. The French version of the LET was then offered to 479 people aged 13 to 72 . All of them responded to the 6 items of the questionnaire on a 5-point Likert scale. Nomological validity was performed using questionnaires from the original version: the Satisfaction with Life Scale, the Generalized Self-Efficacy Scale and the Hospital Anxiety and Depression Scale.

Results: Confirmatory factor analysis validates the unidimensionality of the scale. Multi-group invariance analyses also show invariance for gender but not for age. Finally, the nomological validity is satisfactory and comparable to the original version.

Conclusion: The French version of the LET (LET-F) is an instrument with sufficient psychometric qualities to be used in clinical or research settings. For clinicians, the LET-F can be used as a tool to assess a patient's engagement in life in the aftermath of life events such as illness or grief. For researchers, given the brevity of this questionnaire, it can be easily combined with other instruments, thus allowing for broad-spectrum investigations of well-being behaviors.

\section{Introduction}

In support of the model proposed by Carver and Scheier [1] concerning behavioral self-regulation and personal goal achievement, Scheier, Wrosch, Baum, Cohen, Martire, et al. [2] pursued the concept further by examining how the process of identifying goals that are valued acts as a mechanism by which a person remains behaviorally engaged in life. Valued goals are, in this context, not only objectives, but also reflect the intensity of commitment to attaining these goals, and by inference, the emotions that drive the process of pursuing them. These goals are inherently concrete, meaningful and accessible to consciousness, allowing them to be expressed and evaluated by the individuals themselves. Several tools for strength-based assessment and evaluation have been developed to account for purpose in life such as the Purpose in Life Scale (PIL) [3], the Life Regard Index (LRI) [4], the Life Purpose Questionnaire (LPQ) [5], the Scales of Psychological Well-Being (SPWB) [6], and the Life Attitude Profile Scale (LAP) [7]. According Scheier et al. [2] while these tools are relevant as objective measures of life purpose, valued goals, satisfaction, and psychological well-being, they are often time insensitive (gauging past experience versus current experience), making it difficult to assess changes in purpose in life over time, for example, as a result of pivotal life moments such as illness. These other scales often also measure constructs in addition to purpose in life, such that it is difficult to determine which components within a scale are responsible for producing associations that emerge. It is in this perspective that these authors developed the Life Engagement Test (LET).

The LET is a six-item instrument designed to measure purpose in life by assessing the extent to which people engage in activities they find valuable and significant. This important study describes how psychometric properties of the six items were assessed in eight samples, including four samples of individuals affected by disease [two comprised of cancer patients, one of osteoarthritis patients, and one of spouses of women with osteoarthritis]. Exploratory factor analysis was used to identify a one-factor solution for each of the samples. The LET also showed satisfactory internal consistency for each of the samples ( $\alpha=0.72$ to 0.87 ) and temporal stability evaluated over a four-month period in four samples $\left(r_{s}=0.61\right.$ to 0.76$)$. The convergent and divergent validities of the LET were supported by positive and significant correlations with many health-related psychosocial variables, such as self-control and life satisfaction, as well as negative and significant correlations, such as perceived stress and symptoms of anxiety and depression [2]. The authors also found no significant differences between gender, age or ethnic background.

Since its first implementation, much research has documented the direct, positive and significant links between staying engaged in life and several psychological variables, such as psychological well-being $[8,9]$, life satisfaction $[10,11]$, optimism and hope [12], and feelings of personal resilience [13]. In the context of health-related quality of life, life engagement was observed in cases of individuals with prostate cancer to be positively and significantly correlated with a stronger sense of self, feelings of belonging and positive social connections [14], and was shown to reduce perceived (versus real) disabling symptoms associated with Parkinson's disease [15]. The LET has also been shown to be associated with positive changes in health behaviors, such as increased physical activity [9], reduction in smoking [16] and coping with feelings of loneliness [17].

Other works have shown that life engagement mediates relationships between variables such as wisdom and emotional well-being [18], life satisfaction and personality traits, and is involved in a negative correlation with neuroticism [19-21] and a positive correlation with work ethic [19]. Finally, several studies have proposed that life "Corresponding Author: Prof. Fabienne Lemétayer, Université de Lorraine, APEMaC, F - 57000 Metz, France, Tel: +33 3727483 07; E-mail: fabienne.lemetayer@univ-lorraine.fr

Citation: Lemétayer F, Florquin M, Lepage L, Saez L, Lanfranchi JB (2021) French Validation of the Life Engagement Test Scale. Int J Psychol Behav Anal 7: 176. doi: https://doi.org/10.15344/2455-3867/2021/176

Copyright: (C) 2021 Lemétayer et al. This is an open-access article distributed under the terms of the Creative Commons Attribution License, which permits unrestricted use, distribution, and reproduction in any medium, provided the original author and source are credited. 
engagement acts as a marker for an adjustment process that promotes successful adaptation [22] and "aging well" [23] through continued volunteering and/or volunteer activities after retirement [24].

There are currently two translated versions of the LET, one in Bangladeshi, the other in Japanese. The Bangladeshi version of the LET [11] was validated with a sample of 210 students in a study on the influence of life satisfaction on life engagement. An exploratory factor analysis identified a one-factor model accounting for $46.80 \%$ of the total variance of the Bangladeshi LET. Cronbach's alpha of 0.77 was considered acceptable by the authors. More recently, the Japanese version of LET (LET-J) was validated with two samples of 409 Japanese students (in a test-retest situation) and 439 adult workers [25]. For each sample, exploratory factor analyses confirmed the onefactor structure of LET-J and confirmatory factor analyses revealed good model fits. Cronbach's alphas were also found to be acceptable $(\alpha=0.82$ to 0.86 ). Test-retest reliability for the student sample was also satisfactory $(\mathrm{r}=0.76)$.

To our knowledge, a French translation of the LET does not yet exist. The objective of this study is to examine the reliability and factorial validity of the French version of LET-F from a confirmatory perspective.

\section{Method \\ Participants}

The sample selected allowed for the widest age range. The overall convenience sample consisted of 479 participants, divided into 158 students at the middle and high school levels ( 83 girls and 74 boys and one blank value; median age 15 years [min. 13 years; max. 17 years]), 138 students enrolled in different disciplines (95 women and 43 men; median age 20 years [min. 18 years; max. 25 years]) and 183 adults (154 women, 29 men; median age 45 years [min. 27 years; max. 72 years]). The first two samples are teenagers and young adults in school or college. The third sample is parents of students.

\section{Measures}

All of them completed the French translation of the LET-F questionnaire, which was developed following a multi-stage procedure [26]. The items in the original version were first translated into French by two of the authors. The resulting French version was then translated back into English by a fully bilingual person who was not familiar with the original scale. A committee composed of two of the authors and an independent bilingual expert who confirmed the quality of the back translation against the source language version and judged their equivalence to be satisfactory. As in the original version, the LET-F includes 6 items, with a positive orientation for three items (items 2, 4 and 6) and a negative orientation for the other three items (items 1, 3 and 5). Each item refers to a statement to which the respondent is asked to indicate their level of agreement on a 5-point scale (ranging from 1 "strongly disagree" to 5 "strongly agree").

For nomological validity, the participants answered the LET-F scales successively and responded to the following questionnaires in their French versions.

Satisfaction with Life Scale (SWLS): this scale measures the cognitive part of life satisfaction. It consists of 5 items evaluated in 7 points ranging from 1 "strongly disagree" to 7 "strongly agree". Cronbach's alpha is excellent $(\alpha=.90)[27,28]$.

Int J Psychol Behav Ana

ISSN: 2455-3867
Generalized Self-Efficacy Scale (GSE): this scale measures the ability to perform a new or difficult task, or to cope with adversity. This scale involves 10 items evaluated in 4 points ranging from 1 "strongly disagree" to 4 "strongly agree"; Cronbach's alpha is satisfactory to excellent ( $\alpha=.76$ to .90$)[29,30]$.

Perceived Stress Scale (PSS): this scale assesses the importance with which life events are perceived as threatening, unpredictable and painful. It is composed of 10 items assessed in 5 points ranging from 0 "never" to 4 "very often". Cronbach's alpha is satisfactory $(\alpha=.78)$ $[31,32]$.

Hospital Anxiety and Depression Scale (HADS): this tool is divided into two scales which seek to identify an anxious symptomatology for one and a depressive one for the other, as well as the severity of these symptoms. These two scales include 7 items each with 4 points ranging from 0 "very positive valence" to 3 "very negative valence". Cronbach's alpha is satisfactory to excellent for each scale (HADSAnxiety, $\alpha=.68$ to .93 ; HADS-Depression $\alpha=.67$ to .90 ) $[33,34]$.

All statistical analyses presented below were performed using JASP version 0.12.2. (JASP Team 2020) [35].

\section{Results}

\section{Internal consistency, mean, standard deviation, correlations}

The internal consistency of the French LET-F scale was assessed using the McDonald's omega ( $\omega$ ) wich is based upon the sum of the squared loadings on the general factor [36]. The French LET-F scale has a satisfactory internal consistency with a McDonald's omega $(\omega)$ of .74, comparable to Cronbach's alpha of the original version between .72 and .80 (see samples 1, 4, 7 and 8 composed of participants with no pathology). These results suggest a certain homogeneity between the items of the scale. The item-total (I-T) correlations show a mean correlation of .66, ranging from .61 (item 6) to .77 (item 3), the average correlation between items is .32. These results are presented in Table 1 .

\section{Confirmatory analysis of the French version of the LET}

The factor structure of the scale was verified within the framework of the structural equation models by applying confirmatory factor analysis. Parameter estimates were performed with the Diagonally Weighted Least Squares (DWLS) estimator using the polychoric correlation matrix. This estimator has been evaluated as particularly robust [37] when response scales are ordinal and with skewness and kurtosis showing non-normality of responses (Table 1). The model fit was evaluated on the basis of the following indices and acceptability thresholds: CFI (Comparative Fit Model) $\geq .95$, RMSEA (Root Mean Square Error of Approximation) $\leq .06$, SRMR (Standardized Root Mean Square Residual) $\leq .08$ [38]. Parameter estimates indicate a satisfactory fit to the model in Table 2. Items loadings range from 46 (item 6) to .82 (item 3 ) and the average variance extracted is $32.9 \%$.

\section{LET-F invariance analyses}

At the same time, we tested the LET-F for measurement invariance across gender and age variables by performing multigroup confirmatory factor analyses. Due to missing information, invariance analyses for gender were performed on a sample of 478 participants, divided into 332 women (70\%) and 146 men (30\%) participants. Analysis of measurement invariance for age concerned a sample of 
Citation: Lemétayer F, Florquin M, Lepage L, Saez L, Lanfranchi JB (2021) French Validation of the Life Engagement Test Scale. Int J Psychol Behav Anal 7: 176. doi: https://doi.org/10.15344/2455-3867/2021/176

Page 3 of 6

479 participants, divided into two groups: a first group consisted of 296 participants aged 13 to 25 years $(M=17.58 ; S D=2.88)$ and a second group consisted of 183 participants aged 27 to 72 years (M $=45.04 ; \mathrm{SD}=7.69$ ). For each of these variables, the measurement invariance analysis was tested using four successive nested models $1 /$ the configural invariance model which poses the invariance of the structure in a single dimension between the groups; $2 /$ the metric invariance model which imposes the equality of the saturations between the groups; 3/the scalar invariance model which adds a constraint of equality of the intercepts for the six items between each group; 4/and finally the strict invariance model which, moreover, forces the identity of the measures of residual variance (measurement errors and specific variance). Successive validation of the first three models is at least a prerequisite for all subsequent comparisons between groups [39]. The results of the analyses of invariance are presented in Table 2. Concerning the gender variable, the results show that the differences in $\chi^{2}$ are not significant between the $\mathrm{n}-1$ model and the $\mathrm{n}$ model and that the model fit indices are correct for the models of configural invariance, metric invariance (except RMSEA), scalar invariance and strict invariance, suggesting total invariance for the gender variable.

By contrast, the results pertaining to the age variable reveal significant differences in $\chi^{2}$ and in the adequacy indices between the metric invariance model and the scalar invariance model, too important to consider total invariance for the age variable.

\section{Nomological validity}

This analysis was conducted on a sub-sample of 351 persons (aged 13 to 65 years, $M=50.21,63.4 \%$ of whom were women) of the overall study sample. The size of this sample corresponds to the participants who answered more than $80 \%$ of the selected questionnaires. Table 3 presents the correlations between LET-F scores and the other measures (see Measures section: SWLS, GSE, PSS, HADS). The LET-F score is significantly and positively correlated with measures of life

\begin{tabular}{|c|c|c|c|c|c|}
\hline Items ${ }^{\text {a }}$ & Mean & SD & Sk & $\mathrm{K}$ & $\mathrm{I}-\mathrm{T}$ \\
\hline 1. There is not enough purpose in my life. ${ }^{b}$ & 3.58 & 1.13 & -.42 & -.58 & .63 \\
\hline \multicolumn{6}{|l|}{ Il n'y a pas assez d'objectifs dans ma vie. ${ }^{b}$} \\
\hline 2. To me, the things I do are all worthwhile. & 3.62 & .98 & -.49 & -.09 & .63 \\
\hline \multicolumn{6}{|l|}{ Pour moi, les choses que je fais ont toutes un sens. } \\
\hline 3. Most of what I do seems trivial and unimportant to me. ${ }^{b}$ & 3.97 & 1.06 & -.92 & .14 & .77 \\
\hline \multicolumn{6}{|c|}{ La plupart de ce que je fais me semble sans intérêt et sans importance. ${ }^{b}$} \\
\hline 4. I value my activities a lot. & 4.03 & .86 & -.88 & .95 & .63 \\
\hline \multicolumn{6}{|l|}{ J'apprécie beaucoup mes activités. } \\
\hline 5. I don't care very much about the things I do. ${ }^{\text {b }}$ & 4.02 & 1.04 & -.92 & .16 & .69 \\
\hline \multicolumn{6}{|l|}{ Je n'accorde pas beaucoup d'importance aux choses que je fais. ${ }^{\text {b }}$} \\
\hline 6. I have lots of reasons for living. & 4.16 & .95 & -1.11 & .92 & .61 \\
\hline \multicolumn{6}{|l|}{ J'ai beaucoup de raisons de vivre. } \\
\hline Total LET (mean score) & 3.90 & 1.00 & & & \\
\hline
\end{tabular}

Table 1: Descriptive Analyses, Skewness (Sk), Kurtosis (K), Item-Total (I-T) (n=479).

Note: ${ }^{\text {a }}$ The French scale is available upon request; ${ }^{b}$ Items to be reversed; higher the LET scores correspond to higher levels of life engagement; $\mathrm{SD}$ of Skewness $=.12$; SD of Kurtosis $=.22$

\begin{tabular}{|c|c|c|c|c|c|c|c|c|c|c|c|}
\hline Model fitting & $X^{2}$ & $d f$ & CFI & RMSEA & SRMR & & & & & & \\
\hline & 13.47 & 9 & .99 & .03 & .04 & & & & & & \\
\hline Invariance test & $X^{2}$ & df & CFI & RMSEA & SRMR & $\Delta X^{2}$ & $\Delta \mathrm{df}$ & $\Delta \mathrm{CFI}$ & $\triangle \mathrm{RMSEA}$ & $\triangle \mathrm{SRMR}$ & Decision \\
\hline \multicolumn{12}{|c|}{ Gender $(\mathrm{n}=478 ; 1$ missing datum $)$} \\
\hline M1.Configural & 17.79 & 18 & 1 & $.00^{\mathrm{a}}$ & .04 & & & & & & \\
\hline M2.Metric & 29.99 & 24 & .99 & .03 & .06 & 12.20 & 6 & -.01 & .03 & .01 & Accepted \\
\hline M3.Scalar & 36.49 & 29 & .99 & .03 & .06 & 6.50 & 5 & .00 & .00 & .00 & Accepted \\
\hline M4.Strict & 44.09 & 35 & .98 & .03 & .06 & 7.60 & 6 & -.01 & .00 & .01 & Accepted \\
\hline \multicolumn{12}{|c|}{ Age groups $(n=479)$ [under 26 vs. over 26 years of age] } \\
\hline M1.Configural & 19.99 & 18 & 1 & .02 & .05 & - & - & - & - & - & - \\
\hline M2.Metric & 28.09 & 24 & .99 & .03 & .06 & 8.10 & 6 & -.01 & .01 & .01 & Accepted \\
\hline M3.Scalar & $57.43^{* *}$ & 29 & .95 & .06 & .07 & $29.35^{\star *}$ & 5 & -.05 & .04 & .01 & Rejected \\
\hline M4.Strict & - & - & - & - & - & - & - & - & - & - & - \\
\hline
\end{tabular}

Table 2: Confirmatory factor analysis and analysis of invariance.

Note: ${ }^{\star} \mathrm{p}<.05,{ }^{*} \mathrm{p}<.01$; Metric Invariance Fit Criteria (M2-M1): $\Delta$ CFI $\leq .01, \Delta$ RMSEA $\leq .015$ and $\Delta$ SRMR $\leq .03$; Scalar $(\mathrm{M} 3-\mathrm{M} 2)$ and Strict (M4-M3) Invariances: $\triangle \mathrm{CFI} \leq .01, \Delta \mathrm{RMSEA} \leq .015$ and $\triangle \mathrm{SRMR} \leq .015$ (as recommended by Putnick \& Bornstein, 2016).

${ }^{\text {a }}$ RMSEA $=0$ because $\mathrm{df}>X^{2}$. 
satisfaction and self-efficacy, and negatively correlated with perceived stress, depression, and anxiety.

The LET-F scale shows satisfactory correlations close to those obtained in the original study (see samples 1, 4, 7 and 8), with the exception of self-efficacy (proxy measure of self-mastery in our study), which shows lower correlation. On the other hand, the positive associations with life satisfaction and self-efficacy, and negative associations with perceived stress and depression are comparable to those found in the original study.

\section{Conclusions}

The main objectives of this study were to validate the French version of the LET and to test measurement invariance of LET-F between men and women, and between adolescents/young adults versus adults. The analyses first confirmed the unidimensional structure of the 6-item LET-F, updated in the article by Scheier et al. [2]. The internal consistency of the LET-F was also deemed satisfactory and comparable to those obtained in the samples with no pathologies included in the original English language version. The nomological network of LET-F was also found to be consistent with that found in the original version. Finally, scores observed in the French version shows positive and significant links with well-being variables (life satisfaction and self-efficacy), as well as negative and significant links with adverse variables (perceived stress, and anxiety and depression).

The multigroup confirmatory factor analyses conducted in this study also revealed measurement invariance in the LET-F for gender, confirming that the LET items refer to the same relevant psychological dimension for both women and men respondents. On the other hand, the results revealed differences in response formats according to the age of the respondents, i.e., those under 26 versus those over 26 years of age $^{1}$. Engagement in life through the pursuit, achievement and evolution of personal goals is not expressed with the same importance, nor with the same judgment criteria according to the two age groups. The absence of age invariance does not point to a weakness in the tool, but rather underlines the way in which each group appropriated the items according to its own frame of reference: "Non-invariance can be informative and may lead researchers to important conclusions about how different groups interpret the same construct" [39]. These data are consistent with lifespan theories that consider that there are necessarily developmental differences in the achievement and design of life goals and objectives according to the life cycle in which the individual is situated $[40,41]$.

${ }^{1}$ A second analysis was performed without minors (between 18 and 26 vs. over 26 years of age) which did not improve the model: the M3.Scalar model was still rejected.
Taken together, the results of this research thus provide elements of validation for the French version of the LET-F that seem sufficient to envisage its use in the field of psychological research. With its short format ( 6 items), the LET-F is a brief and relevant measurement scale for assessing respondents' perception of engagement in the lives of the native French speaking population. For Scheier et al. [2] engagement in life is one of the essential components of psychological well-being. Further studies in this field should provide a better understanding of the influence of engagement in life and its varied role in the context of health behaviors surrounding treatment adherence, disease management, coping strategies, behavioral changes, etc., particularly in cases of chronic diseases, from adolescence to old age. These results also lead us to consider the interest and implications of LET-F in therapeutic management. Indeed, it is likely that people who lack purpose in life encounter difficulties in achieving the goals they value because they are too demanding or may have become inaccessible, for example. These perceived difficulties may lead an individual to become less energetically engaged in life, that could lead to discomfort and, potentially, to subsequent manifestations of depression in the most severe cases. This highlights the critical importance for health professionals to identify low levels of purpose in life in their patients and to work with them towards identifying valued life goals, importantly to potentially avoid symptoms associated with depression that could further derail efforts to deal with existing health problems.

In conclusion, the French version of the LET is an instrument with sufficient psychometric qualities to be used in clinical or research settings. For clinicians, the LET-F can be used as a tool to assess a patient's sense of purpose in life based on life events such as illness and bereavement. For researchers, given its brevity, it can be easily combined with other instruments, thus allowing for broad-spectrum investigations of well-being behaviors. However, this study has one main limitation that should guide future research. A time-stability (test-retest) evaluation of the LET-F would provide valuable insight into the stability of the results obtained, which would also allow comparison with the data obtained in the original version [2] and in the Japanese version [25].

\section{Competing Interests}

The authors declare that they have no competing interests.

\section{Authors' Contributions}

Conception and design: Fabienne Lemétayer and Jean-Baptiste Lanfranchi

Collection: Manon Florquin and Laura Lepage

Analysis and interpretation of data: Fabienne Lemétayer and JeanBaptiste Lanfranchi

\begin{tabular}{|l|c|c|c|c|c|}
\hline Measures & Mean & SD & $\alpha$ & Zero-order correlations & Original LET Zero-order correlations \\
\hline Life engagement & 23.43 & 3.93 & .73 & & $.51^{\star *}$ \\
\hline Life satisfaction & 24.30 & 6.61 & .87 & $.50^{\star *}$ & $.47^{\star *}$ \\
\hline Self-efficacy / Self-mastery & 28.69 & 4.96 & .76 & $.39^{\star *}$ & $-.46^{* *}$ \\
\hline Perceived stress & 27.51 & 6.97 & .74 & $-.43^{\star *}$ &.- \\
\hline Anxiety & 8.64 & 4.13 & .86 & $-.29^{\star *}$ & $-.42^{* *}$ \\
\hline Depression & 4.67 & 3.60 & .85 & $-.44^{\star *}$ & \\
\hline
\end{tabular}

Table 3: Correlations between LET-F scores and subjective measures of well-being $(\mathrm{n}=351)$.

Note: ${ }^{\star} \mathrm{p}<.05,{ }^{\star \star} \mathrm{p}<.01$; original LET (Scheier et al., 2006). 
Citation: Lemétayer F, Florquin M, Lepage L, Saez L, Lanfranchi JB (2021) French Validation of the Life Engagement Test Scale. Int J Psychol Behav Anal 7: 176. doi: https://doi.org/10.15344/2455-3867/2021/176

Page 5 of 6

Drafting the article: Fabienne Lemétayer and Jean-Baptiste Lanfranchi Participation in revising the manuscript critically and gave their final approval of the version submitted: Fabienne Lemétayer, Jean-Baptiste Lanfranchi, Manon Florquin, Laura Lepage and Laura Saez

\section{Ethics Approvals}

Ethical approval has been obtained by the Institutional Review Board (reference number: $\mathrm{N}^{\circ}$ 16-324/ MR 003: 2009422).

\section{Consent to Participate}

Informed consent was obtained from all individual participants included in the study.

Informed consent was obtained from legal guardians.

Written informed consent was obtained from the parents.

\section{Availibility of Data and Material}

Data set is available at: https://osf.io/xyu4b/?view_only=b927c10b0 7f94ed3a2c26e6daf7aabdc

\section{Acknowledgements}

The authors thank Prof. Michael Scheier for his agreement to the translation and validation of the French version of the LET.

\section{References}

1. Carver CS, Scheier MF (1998) On the Self-Regulation of Behavior. New York: Cambridge University Press, UK

2. Scheier MF, Wrosch C, Baum A, Cohen S, Martire LM, et al. (2006) The Life Engagement Test: assessing purpose in life. J Behav Med 29: 291-298.

3. Crumbaugh JC, Maholick LT (1964) An experimental study in existentialism: The psychometric approach to Frankl's concept of noogenic neurosis. J Clin Psychol 20: 200-207.

4. Battista J, Almond R (1973) The development of meaning in life. Psychiatry 36: 409-427.

5. Hablas R, Hutzell R (1982) The Life Purpose Questionnaire: An alternative to the Purpose-in-Life test for geriatric, neuropsychiatric patients. In: Wawrytko SA (Ed) Analecta Frankliana: The proceedings of the First World Congress of Logotherapy, Berkeley, CA: Strawberry Hill, USA.

6. Ryff CD, Keyes CL (1995) The structure of psychological well-being revisited J Personal Soc Psychol 69: 719-727.

7. Reker GT (1981) The Life Attitude Profile (LAP): A multidimensiona instrument for assessing attitudes toward life. Canad J Behav Sci 13: 264273

8. Morton E, Colby A, Bundick M, Remington K (2018) Hiding in plain sight: Older US purpose exemplars. J Posit Psychol 14: 1-11.

9. Lewis P, Kimiecik J, Horn T, Zullig KJ, Ward RM, et al. (2014) Can becoming myself influence my health?: Exploring the effects of a eudaimonicenhancement process on psychological indicators of well-being and physical activity. ARQOL 9: 643-665.

10. Lewis AD, Huebner ES, Malone PS, Valois RF (2011) Life satisfaction and student engagement in adolescents. J Youth Adolesc 40: 249-262.

11. Shahnaz I, Rezaul Karim AK (2014) Life Satisfaction as a Determinant of Life Engagement. Bangladesh Psychological Studies 24: 1-16.

12. Moe JL, Dupuy PJ, Laux JM (2008) The relationship between LGBQ identity development and hope, optimism, and life engagement. J LGBT Issues Couns 2: 199-215.

13. Kees M, Rosenblum K (2015) Evaluation of a psychological health and resilience intervention for military spouses: A pilot study. Psychol Serv 12: 222.

Int J Psychol Behav Anal

ISSN: 2455-3867
14. Levy A, Cartwright T (2015) Men's strategies for preserving emotional wellbeing in advanced prostate cancer: An interpretative phenomenological analysis. Psychol Health 30: 1164-1182.

15. Vescovelli F, Sarti D, Ruini C (2018) Subjective and psychological well-being in Parkinson's Disease: A systematic review. Acta Neurol Scand 138: 12-23.

16. Ruisoto $P$, Cacho R, López-Goñi JJ, Vaca S, Jiménez $M$, et al. (2016) Prevalence and profile of alcohol consumption among university students in Ecuador. Gac Sanit 30: 370-374.

17. Neville S, Adams J, Montayre J, Larmer P, Garrett N, et al. (2018) Loneliness in Men 60 Years and Over: The Association With Purpose in Life. Am J Mens Health 12: 730-739.

18. Etezadi S, Pushkar D (2013) Why are wise people happier? An explanatory model of wisdom and emotional well-being in older adults. J Happiness Stud 14: 929-950.

19. Brygola E (2018) Personality traits and subjective well-being with regard to problem of infertility: The mediating role of implicit self-theories and lifeengagement. Pol Psychol Bull 49: 141-148.

20. Miciuk LR, Jankowski T, Laskowska A, Oles P (2016) Positive Orientation and the Five-Factor Model. Pol Psychol Bull 47: 141-148.

21. Sobol-Kwapinska M (2016) Calm down-It's only neuroticism. Time perspectives as moderators and mediators of the relationship between neuroticism and well-being. Pers Indiv Differ 94: 64-71.

22. Marshall E, Mackenzie L (2008) Adjustment to residential care: The experience of newly admitted residents to hostel accommodation in Australia. Aust Occup Ther J 55: 123-132.

23. Pearson EL, Windsor TD, Crisp DA, Butterworth P, Pilkington PD, et al. (2013) Normative data and longitudinal invariance of the Life Engagement Test (LET) in a community sample of older adults. Qual Life Res 22: 327-331.

24. Schwingel A, Niti MM, Tang C, Ng TP (2009) Continued work employment and volunteerism and mental well-being of older adults: Singapore longitudinal ageing studies. Age Ageing 38: 531-537.

25. Sumi K (2018) The Japanese Translation of the Life Engagement Test Reliability and Construct Validity in a College Student Population and a Working Adult Population. IJPBA 4: 136.

26. Guillemin F, Bombardier C, Beaton D (1993) Cross-cultural adaptation of health related quality of life measures: literature review and proposed guidelines. J Clin Epidemiol 46: 1417-1432.

27. Diener E, Emmons RA, Larson RJ, Griffin S (1985) The satisfaction with life scale. J Pers Assess 49: 71-75.

28. Blais MR, Vallerand RJ, Pelletier LG, Brière NM (1989) L'Échelle de satisfaction de vie : Validation canadienne-française du "Satisfaction with Life Scale". Rev Can Sci Comport 21: 210-223.

29. Schwarzer R, Jerusalem M (1995) Generalized Self-Efficacy scale. In Weinman J, Wright $S$, Johnston M (Eds) Measures in health psychology: A user's portfolio. Causal and control beliefs Windsor, UK: NFER-Nelson, UK.

30. Dumont $M$, Schwarzer $R$, Jerusalem M (2000) Adaptation française de l'auto-efficacité généralisée.

31. Cohen S, Kamarck T, Mermelstein R (1983) A global measure of perceived stress. J Health Soc Behav 24: 385-396.

32. Quintard B (2001) Le concept de stress et ses méthodes d'évaluation. Rech Soins Infirm 67: 46-67.

33. Zigmond AS, Snaith RP (1983) The hospital anxiety and depression scale. Acta Psychiat Scand 67: 361-370.

34. Lepine JP, Godchau $M$, Brun $P$, Lemperière $T$ (1985) Evaluation de l'anxiété et de la dépression chez des patients hospitalisés dans un service de médecine interne. Ann Med Psychol 143: 175-189.

35. JASP Team (2020) JASP (Version 0.12.2).

36. Revelle W, Zinbarg RE (2009) Coefficients Alpha, Beta, Omega, and the glb: Comments on Sijtsma. Psychometrika 74: 145.

37. Li C (2016) Confirmatory factor analysis with ordinal data: Comparing robust maximum likelihood and diagonally weighted least squares. Behav Res Ther 48: 936-949.

38. Hu L, Bentler PM (1999) Cutoff criteria for fit indexes in covariance structure analysis: Conventional criteria versus new alternatives. Struct Equ Model 6: 1-55. 
Citation: Lemétayer F, Florquin M, Lepage L, Saez L, Lanfranchi JB (2021) French Validation of the Life Engagement Test Scale. Int J Psychol Behav Anal 7: 176. doi: https://doi.org/10.15344/2455-3867/2021/176

Page 6 of 6

39. Putnick DL, Bornstein MH (2016) Measurement Invariance Conventions and Reporting: The State of the Art and Future Directions for Psychologica Research. Dev Rev 41: 71-90.

40. Heckhausen J, Kay JS (2018) Motives, goals, and well-being throughout the lifespan. In: Maddux JE (Ed) Frontiers of social psychology. Subjective wellbeing and life satisfaction, Routledge Books, UK.

41. Heckhausen J, Wrosch C, Schulz R (2010) A motivational theory of life-span development. Psychol Rev 117: 32-60. 